06.1

\title{
Усиление гидрофобных свойств структур ZnO золотым покрытием
}

\author{
() А.Э. Муслимов, В.М. Каневский \\ Федеральный научно-исследовательский центр „Кристаллография и фотоника“ РАН, \\ Москва, Россия \\ E-mail: amuslimov@mail.ru
}

Поступило в Редакцию 23 августа 2021 г.

В окончательной редакции 29 ноября 2021 г.

Принято к публикации 29 ноября 2021 г.

\begin{abstract}
Обнаружен эффект усиления гидрофобных свойств ансамбля микро- и наноструктур ZnO в результате покрытия золотом. Впервые показано, что покрытие ансамбля микро- и наностержней ZnO слоем золота приводит к резкому увеличению краевого угла смачивания с 145 до $168^{\circ}$ (объем капли воды $5 \mathrm{~mm}^{3}$ ) и снижению времени перехода гидрофобность/гидрофильность при ультрафиолетовом облучении.
\end{abstract}

Ключевые слова: $\mathrm{ZnO}$, золото, супергидрофобный.

DOI: 10.21883/PJTF.2022.04.52087.19002

Интерес к супергидрофобным покрытиям прежде всего обусловлен их высокой водонепроницаемостью, стойкостью к коррозии и обледенению, устойчивостью к биообрастанию, а также различным видам загрязнений. Тем более важно использование материалов с супергидрофобными свойствами в качестве элементов современной наноэлектроники. К сожалению, традиционно используемые в наноэлектронике материалы не обладают гидрофобными свойствами, и зачастую требуется специальная подготовка их поверхности. Например, в кремниевых технологиях применяется металлстимулированное травление [1], которое позволяет формировать пористую поверхность с высоким значением краевого угла смачивания. Другим примером является применение поверхностей с многомодальной шероховатостью. В [2] для образцов $\mathrm{ZnO}$ с многомодальной шероховатостью поверхности было достигнуто супергидрофобное состояние с краевым углом, равным $151^{\circ}$. Еще одной проблемой является необходимость нанесения золотых контактов к различным элементам электронной платформы, которые могут служить дополнительными центрами адсорбции воды. Вообще говоря, споры о гидрофильных и гидрофобных свойствах золота идут давно. Согласно выводам, сделанным в [3], чистая поверхность золота является гидрофильной. Однако загрязнение поверхности золота значительно снижает ее смачиваемость. Наряду с этим известны результаты применения [4] этапов микроструктурирования и последующего покрытия тиолом поверхности золота для перевода ее в гидрофобное состояние. Работ, посвященных влиянию покрытия золотом на гидрофобные свойства различных материалов, в частности оксида цинка, в литературе не обнаружено. При этом система $\mathrm{Au}-\mathrm{ZnO}$ применяется в электронных устройствах; соответственно, предъявляются высокие требования к ее эксплуатационным характеристикам. Золото отличается неполярной кристаллической структурой, обладает хорошей адгезией к $\mathrm{ZnO}$, и это является предпосылкой к усилению гидрофобности $\mathrm{ZnO}$, покрытого золотом. В настоящей работе приводится сравнительный анализ гидрофобных свойств (контактный угол смачивания, угол скольжения, переключение гидрофобность/гидрофильность) исходно чистой поверхности $\mathrm{ZnO}$ и поверхности с золотым покрытием с различной морфологией.

Образец $\mathrm{ZnO}$ с развитой микроструктурой поверхности на подложках сапфира (образец типа I) был сформирован методом самокаталитического синтеза из газовой фазы. Осаждение $\mathrm{ZnO}$ осуществлялось в зоне роста из газовой фазы, состоящей из паров цинка и газовой смеси аргона и кислорода. Реактор предварительно вакуумировался до давления $10 \mathrm{~Pa}$. Для формирования специфической микроморфологии $\mathrm{ZnO}$ температура в зоне испарения цинка на завершающем этапе роста понижалась.

Осаждение золота на часть образца $\mathrm{ZnO}$ (образец типа II) осуществлялось в установке термического напыления ВН-2000. Вакуум не хуже $10^{-6} \mathrm{~Pa}$. Толщина слоя золота контролировалась с помощью кварцевого измерителя толщины КИТ-1. Для исследования влияния микроморфологии золотого покрытия на гидрофобные свойства образец типа II отжигался в атмосферных условиях при температуре $650^{\circ} \mathrm{C}$ в трубчатой печи.

Дополнительно для сравнения был синтезирован образец сплошной пленки золота на сапфире.

Микроскопические исследования проводились на растровом электронном микроскопе (РЭМ) Jeol Neoscope 2 (ЈСМ-6000), оснащенном энергодисперсионным рентгеновским микроанализатором. Для анализа гидрофобности/гидрофильности микроструктурированной чистой и покрытой золотом поверхности оксида цинка применялась методика „сидячей капли“. Капля дистиллированной воды объемом порядка $5 \mathrm{~mm}^{3}$ с помощью шприца помещалась на горизонтальную поверхность образца. Оптическая визуализация капли на поверхности осуществлялась с помощью цифровой фотокамеры. Контактный угол определялся по методике, 
$a$

$b$

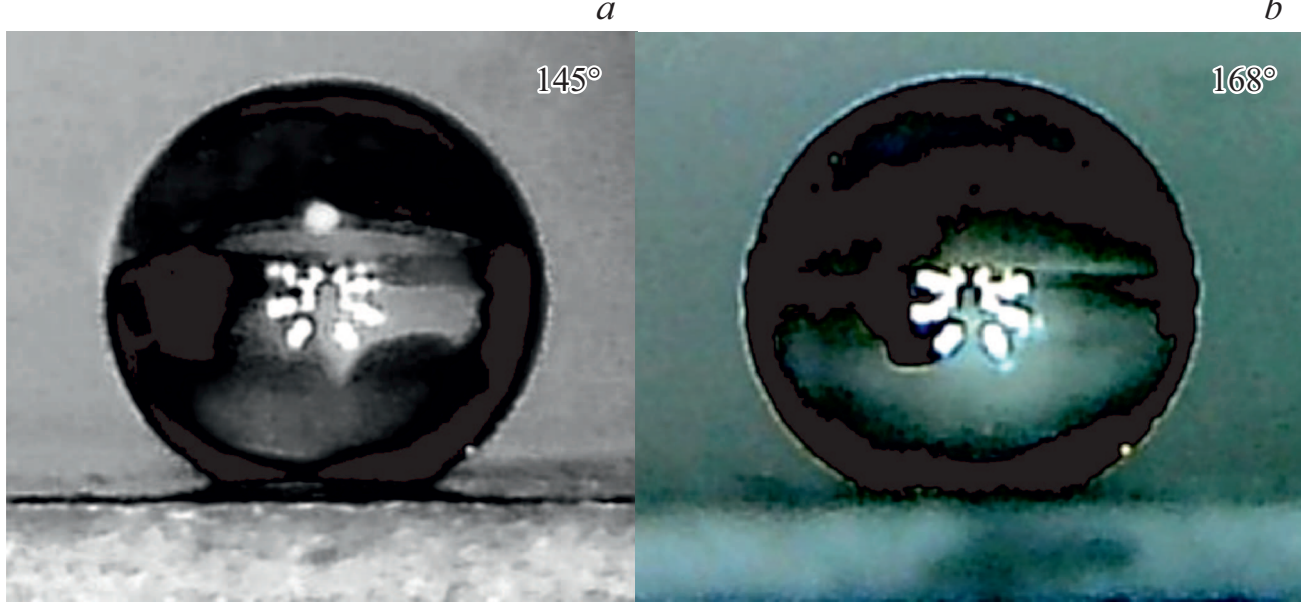

Рис. 1. Фотографии капель воды на поверхности образцов ZnO с указанием контактных углов. $a-$ тип I, $b-$ тип II.

описанной в [5]. Оптические исследования проводились с использованием оптического микроскопа Levenhuk. Исследование процесса переключения гидрофобность/гидрофильность осуществлялось с помощью ультрафиолетового светодиода (максимум излучения $375 \mathrm{~nm}$ ).

Образец типа I по данным электронной микроскопии представлял собой ансамбль гексагональных микростержней $\mathrm{ZnO}$ диаметром до $1 \mu \mathrm{m}$, из торцов которых продолжались заостренные наностержни $\mathrm{ZnO}$. Длина и диаметр наностержней составляли 3-4 $\mu \mathrm{m}$ и 100-150 nm соответственно. Микроморфология поверхности образца $\mathrm{ZnO}$ (тип II) после осаждения золота толщиной порядка $60 \mathrm{~nm}$ практически не изменилась. Присутствие золота ( 2 at.\%) обнаруживалось лишь на спектрах энергодисперсионного рентгеновского микроанализа.

Формирование специфической микроструктуры $\mathrm{ZnO}$ в условиях нашего эксперимента вполне закономерно. На начальном этапе формируются гексагональные микростержни $\mathrm{ZnO}$ по механизму пар-жидкость-кристалл. Катализатором их роста являются жидкие островки цинка на подложке. Молекулы кислорода диффундируют сквозь пары цинка к подложке, вступают в реакцию с цинком на подложке с образованием оксида цинка. В условиях низкой концентрации кислорода, управляя температурой в зоне испарения цинка, довольно легко контролировать диаметр растущих структур ZnO. Уменьшение диаметра стержней $\mathrm{ZnO}$ достигается снижением температуры в зоне испарителя цинка на завершающей стадии синтеза. Инициируется рост наностержня $\mathrm{ZnO}$ из капли цинка уменьшенного размера на торце материнского микростержня. В дальнейшем путем постепенного снижения концентрации цинка в газовой фазе рост наностержня $\mathrm{ZnO}$ полностью блокируется с образованием заострения на конце.

На следующем этапе исследовались гидрофобные свойства поверхности полученных образцов. Наносилась капля воды объемом $5 \mathrm{~mm}^{3}$. Судя по форме капли и величине контактного угла $\theta=145^{\circ}$ (рис. $1, a$ ), можно утверждать, что на поверхности данного образца реализуется состояние Касси-Бакстера [5]. Совокупность микро- и наностержней $\mathrm{ZnO}$ формирует поверхность со сложной морфологией и позволяет реализовать „эффект лотоса“ [6]. Идеально гладкая поверхность $\mathrm{ZnO}$ является высокогидрофильной, и, согласно [7], контактный угол смачивания составляет не более $5^{\circ}$. Контакт капли воды c $\mathrm{ZnO}$ минимизирован, и основную поверхность раздела фаз формирует область соприкосновения капли с воздушной прослойкой, заполняющей микропоры в толще ZnO. В соответствии с моделью Касси-Бакстера [5] с учетом того, что угол смачивания газообразной фазы с жидкостью составляет $180^{\circ}$, оценка доли площади взаимодействия $\mathrm{ZnO}$-жидкость для образца типа I дает 0.18 .

Аномально высокая гидрофобность (увеличение краевого угла смачивания до $168^{\circ}$ ) наблюдается (рис. $\left.1, b\right)$ в области покрытия структуры $\mathrm{ZnO}$ слоем золота (тип II). Следует заметить, что подобные высокие значения краевого угла смачивания наблюдались ранее лишь для структур $\mathrm{ZnO}$ типа „коралл“ с полимерным покрытием [8]. Измеренный контактный угол смачивания для поверхности сплошной пленки золота $\sim 63^{\circ}$, что свидетельствует о ее слабой смачиваемости. Другим фактором усиления гидрофобности образца типа II может являться возможное увеличение или изменение структуры шероховатости в процессе покрытия золотом. По данным РЭМ, заметных изменений морфологии структур $\mathrm{ZnO}$ после осаждения на них слоя золота, не наблюдается. В этом случае вряд ли обоснованно связывать увеличение контактного угла смачиваемости с увеличением шероховатости боковых поверхностей нано- и микростержней $\mathrm{ZnO}$ после нанесения золота. Полагая, что доля площади взаимодействия $\mathrm{ZnO}$-жидкость после покрытия образца типа I золо- 


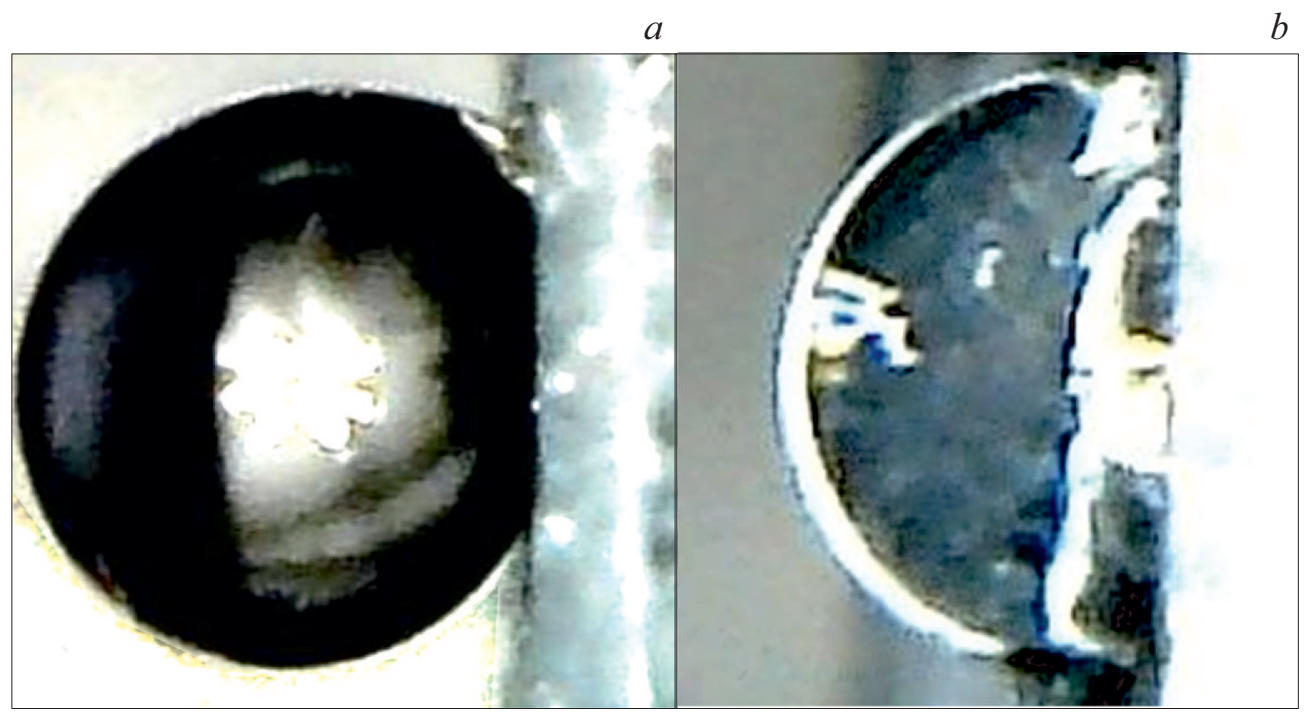

Pис. 2. Фотографии капель воды на поверхности образцов $\mathrm{ZnO}$, наклоненных под углом $\sim 90^{\circ} . a-$ тип I, $b-$ тип II.

том не изменилась, усиление гидрофобности образца в целом можно связать с уменьшением смачиваемости (повышением гидрофобной составляющей) в каждой области контакта. Интересный результат обнаружился в экспериментах с наклоном образцов (время наклона $5 \mathrm{~s})$. Образцы типа I и II с каплями воды наклонялись на $90^{\circ}$ в вертикальной плоскости, т. е. до вертикального положения. Как показали результаты (рис. 2), для образца типа I площадь соприкосновения капли с поверхностью образца практически не изменилась, при этом сама капля наклонилась под действием силы тяжести. Для образца типа II наблюдалось резкое уменьшение краевого угла и увеличение площади соприкосновения капли с поверхностью образца. Следует отметить, что скатывания капли воды с поверхности образцов даже при таком значительном наклоне не наблюдалось.

Отличительной особенностью вюрцитной структуры $\mathrm{ZnO}$ является наличие полярных и неполярных направлений. Острие наностержней располагается вдоль полярной оси $c$ и заканчивается ионами $\mathrm{Zn}^{+}$, на которые легко осаждаются полярные молекулы воды. Боковые грани гексагональных стержней $\mathrm{ZnO}$ образованы неполярными $m$-плоскостями [9]. Расчеты [10] показывают, что молекулы воды на $m$-плоскостях $\mathrm{ZnO}$ агрегируют и диссоциируют, обеспечивая стабильное гидрофильное состояние поверхности. Таким образом, гладкая поверхность $\mathrm{ZnO}$ является высокогидрофильной (контактный угол смачивания менее $5^{\circ}$ ), что подтверждают результаты [7]. С этим связано то, что в случае наклона чистого образца ZnO (тип I) скатывания капли воды, а также сползания нижнего края не наблюдается. Расширение капли при наклоне образца $\mathrm{ZnO}$ с золотым покрытием (тип II) можно объяснить стремлением к уменьшению энергии границы фаз капля- $\mathrm{ZnO} / \mathrm{Au}$ и выполнением условия $\sigma_{s l} \ll \sigma_{s v}$ (поверхностные энергии на границе раздела фаз твердое тело-жидкость и твердое тело-газ соответственно) между удельными свободными энергиями участвующих поверхностей. В целом наблюдаемые эффекты можно связать со сложным характером взаимодействия молекул воды с поверхностью золота [11]. Контактный угол смачивания даже для гладкой поверхности золота представлен в широком диапазоне $30-80^{\circ}$ (по данным обзорного исследования [3]). Предположительно основную роль при взаимодействии молекул воды с поверхностью золота может играть водородная связь $\mathrm{Au}-\mathrm{H}[12]$, энергия которой, к сожалению, неизвестна. C другой стороны [3], наличие даже незначительных загрязнений (менее монослоя углерода) снижает смачиваемость золотого покрытия. С учетом того, что для сплошной пленки золота контактный угол смачивания $\sim 63^{\circ}$, можно сделать вывод о присутствии загрязнения. Еще одним фактором может являться неоднородность покрытия золотом структуры $\mathrm{ZnO}$ со сложным микрои нанорельефом. Для обнаружения влияния микроморфологии покрытия золота образец типа II отжигался. В процессе термообработки золотое покрытие коагулировало, однако значительного влияния на гидрофобность образца типа II не оказало (рис. 3, образец $\mathrm{ZnO} / \mathrm{Au})$. Изменение контактного угла наблюдалось в пределах погрешности. При этом был обнаружен эффект снижения (до $10 \mathrm{~min}$ ) времени перехода гидрофобность/гидрофильность при ультрафиолетовом облучении. Для сравнения отметим, что за это же время на чистой поверхности $\mathrm{ZnO}$ наблюдается уменьшение контактного угла и размеров капли воды.

Таким образом, в работе впервые обнаружен эффект усиления супергидрофобных свойств ансамбля микрои наноструктур $\mathrm{ZnO}$ в результате покрытия золотом. С использованием специального режима осаждения был получен ансамбль гексагональных микростержней $\mathrm{ZnO}$ 


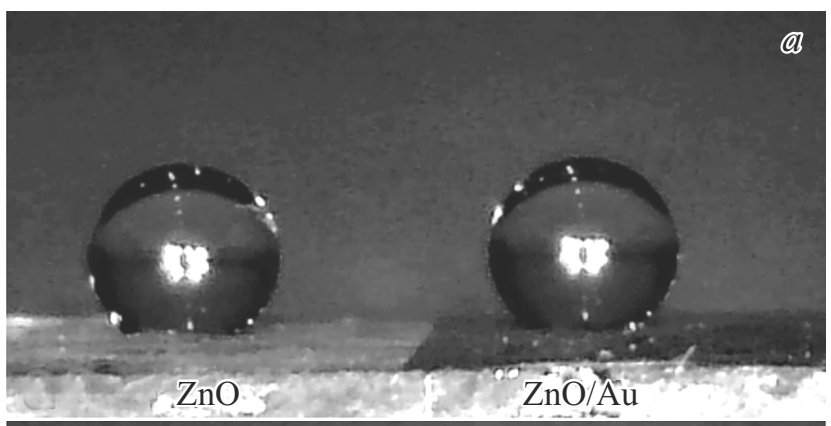

b

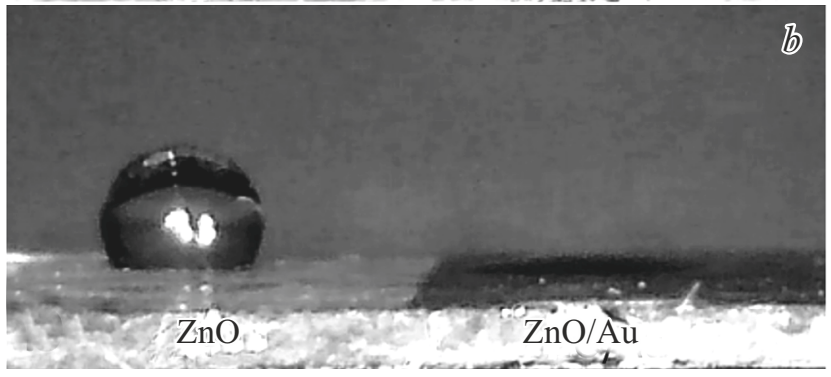

Рис. 3. Исследование процесса переключения гидрофобность/гидрофильность термообработанных образцов $\mathrm{ZnO}$ (типы I и II) при ультрафиолетовом облучении. $a-$ до облучения, $b$ - через $10 \mathrm{~min}$ после облучения.

диаметром до $1 \mu \mathrm{m}$, из торцов которых продолжались заостренные наностержни $\mathrm{ZnO}$, что обеспечило формирование сложной топографии поверхности с многомодальной шероховатостью. Покрытие ансамбля микрои наноструктур $\mathrm{ZnO}$ слоем золота толщиной порядка $60 \mathrm{~nm}$ привело к значительному усилению их супергидрофобных свойств. Величина краевого угла смачивания возросла с 145 до $168^{\circ}$ (объем капли воды $5 \mathrm{~mm}^{3}$ ). При этом наблюдается снижение времени перехода гидрофобность/гидрофильность при ультрафиолетовом облучении. Приведенные результаты могут быть интересны с точки зрения применения системы $\mathrm{Au}-\mathrm{ZnO}$ в электронных устройствах и повышения их эксплуатационных характеристик.

\section{Благодарности}

Авторы выражают благодарность Л.А. Задорожной и А.М. Ополченцеву за помощь в подготовке образцов.

\section{Финансирование работы}

Исследования осуществлялись с использованием оборудования ЦКП ФНИЦ „Кристаллография и фотоника“ в рамках выполнения работ по государственным заданиям ФНИЦ „Кристаллография и фотоника“ РАН, а также при поддержке Российского фонда фундаментальных исследований (грант № 20-0800598).

\section{Конфликт интересов}

Авторы заявляют, что у них нет конфликта интересов.

\section{Список литературы}

[1] О.В. Воловликова, С.А. Гаврилов, Г.О. Силаков, А.В. Железнякова, А.А. Дудин, Электрохимия, 55 (12), 1452 (2019). DOI: 10.1134/S0424857019120181 [O.V. Volovlikova, S.A. Gavrilov, G.O. Silakov, A.V. Zheleznyakova, A.A. Dudin, Russ. J. Electrochem., 55 (12), 1186 (2019). DOI: 10.1134/S1023193519120188].

[2] А.Э. Муслимов, А.Ш. Асваров, Н.С. Шабанов, В.М. Каневский, Письма в ЖТФ, 46 (19), 15 (2020). DOI: 10.21883/PJTF.2020.19.50037.18371 [A.E. Muslimov, A.S. Asvarov, N.S. Shabanov, V.M. Kanevsky, Tech. Phys. Lett., 46 (10), 954 (2020). DOI: 10.1134/S1063785020100107].

[3] T. Smith, J. Coll. Interface Sci., 75 (1), 51 (1980). DOI: 10.1016/0021-9797(80)90348-3

[4] H. Notsu, W. Kubo, I. Shitanda, T. Tatsuma, J. Mater. Chem., 15 (15), 1523 (2005). DOI: 10.1039/B418884E

[5] Y. Yuan, T.R. Lee, in: Surface science techniques, ed. by G. Bracco, B. Holst. Springer Ser. in Surface Sciences (Springer, Berlin-Heidelberg, 2013), vol. 51, p. 3. DOI: $10.1007 / 978-3-642-34243-1$

[6] W. Choi, A. Tuteja, J.M. Mabry, R.E. Cohen, G.H. McKinley, J. Coll. Interface Sci., 339 (1), 208 (2009). DOI: 10.1016/j.jcis.2009.07.027

[7] M. Srivastava, B.B.J. Basu, K.S. Rajam, J. Nanotechnol., 2011, 392754 (2011). DOI: 10.1155/2011/392754

[8] J. Wu, J. Xia, W. Lei, B. Wang, PLoS ONE, 5 (12), e14475 (2010). DOI: 10.1371/journal.pone.0014475

[9] Z.L. Wang, J. Phys.: Condens. Matter., 16, R829 (2004). DOI: $10.1088 / 0953-8984 / 16 / 25 / R 01$

[10] S. Kenmoe, P.U. Biedermann, Phys. Chem. Chem. Phys., 19 (2), 1466 (2017). DOI: 10.1039/c6cp07516a

[11] J. Canning, N. Tzoumis, J.K. Beattie, B.C. Gibson, E. Ilagan, Chem. Commun., 50 (65), 9172 (2014). DOI: $10.1039 / \mathrm{c} 4 \mathrm{cc} 02492 \mathrm{c}$

[12] M. Bakar, M. Sugiuchi, M. Iwasaki, Nature Commun., 8, 576 (2017). DOI: $10.1038 / \mathrm{s} 41467-017-00720-3$ 